\title{
Glucocorticoids in Mate Choice
}

Fhionna R. Moore

Additional information is available at the end of the chapter

http://dx.doi.org/10.5772/51433

\section{Introduction}

Choosing the right mate is fundamental to reproductive success. Selecting the right genes with which to combine one's own increases the chances of offspring survival and reproduction. Choosing wisely, then, can increase the number of copies of genetic material being passed on to future generations. This means that it serves an individual well to signal their own strengths and qualities in order to attract mates, and it serves the opposite sex well to express preferences for honest signals of mate quality. As opposed to natural selection (the process by which traits which confer a survival advantage are selected for [1]), sexual selection is selection for those traits that confer benefits in terms of attracting, and mating with, members of the opposite sex [2]. Such sexually selected traits often serve to reduce the chances of survival and their adaptive function is solely to increase an individual's mating success. Classic examples are the peacock's extravagant tail plumage that dramatically increases chances of predation [3], and the display of the bowerbird, which bears a heavy energetic cost to construct [4]. These traits have evolved as the benefits of attracting members of the opposite sex outweigh the associated costs to survival. In order for these social signalling systems to work, however, the signal must provide an honest indication of quality $[5,6]$. If it is possible to cheat, the system could not function: elaborate displays would no longer signal a genetic benefit for offspring.

Honest signals of mate-choice relevant qualities fall into two broad categories, both of which are impossible to fake. These are qualities that infer "indirect" benefits, which include heritable traits such as a strong immune system [7,8], and those that infer "direct" benefits, such as the ability and willingness to provide resources and parental care. Over the last decade evidence has accumulated to suggest that the physiological stress response may be linked to both sets of characteristics. For one, the glucocorticoid hormones modulate the immune system, meaning that stress may influence health and condition which, in turn, influence the ability of an individual to mate successfully or to provision and care for offspring $[9,10]$. Alternatively, between-individual variation in dimensions of the stress 
response such as the peak levels of glucocorticoids secreted in response to a stressor and the time taken for levels to return to baseline are heritable, meaning that individuals are likely to differ in their ability to cope effectively and efficiently with stress [11, 12]. There is a growing body of evidence that demonstrates that females assess the glucocorticoid status of potential opposite sex partners, and express preferences for cues to low stress.

Given the role of hormones in directing the allocation of energy to different physiological and behavioural functions, it is not surprising that they have received attention in the context of mate choice and sexual signalling. Testosterone has received by far the most attention in this domain due to evidence for its role in the development of those male traits used to attract females. Among many other traits testosterone is, for example, consistently found to relate to the vitality of sexually selected plumage colouration in birds (see for example $[13,14])$, the size and strength of antlers in red deer stags (Cervus elaphus; see for example $[15,16]$ ) and the intensity and complexity of bird song (see for example $[17,18])$. In essence, high testosterone results in a strong signal that, in turn, translates into mating success. In the Immunocompetence Handicap Hypothesis of sexual selection [7], testosterone-dependent traits are proposed to provide an honest signal of the strength of a male's immune system due to the hormone's immunosuppressive actions. In other words, only those males who have inherited a robust immune system can afford the costs of the elevated testosterone required for development of extravagant sexual signals. A large antlered red deer stag, then, is signalling his superior immune system. This, in turn, should attract female mates who seek to acquire such "good genes" for their offspring. In the years since its inception, this model has generated a huge body of research, with a Google Scholar search for "Immunocompetence Handicap" returning 2, 500 publications.

Despite providing an elegant explanation for the maintenance of variation in the expression of sexual signals as honest indicators of quality, and good evidence that such traits are linked to parasite resistance, however, one of the Immunocompetence Handicap model's fundamental assumptions fails to receive adequate support. Reviews show inconsistency in evidence for immunosuppression by testosterone [19]. As a consequence, biologists have attempted to address this weakness by identifying additional or alternative endocrinological factors that may contribute to the system. And this is where the glucocorticoids have attracted attention. These stress hormones are correlated with testosterone across species (albeit the direction of the relationship is variable; see for example [11, 20 - 23]) and modulate immune function [24] and body condition [9, 10]. In [11], for example, the authors demonstrated that an immunosuppressive effect of testosterone in the house sparrow (Passer domesticus) disappeared when the effects of the primary avian glucocorticoid corticosterone were controlled for statistically. They concluded that the effects of testosterone on the immune system may be mediated or moderated by co-occurring levels of glucocorticoids. More recently, it has been suggested that low levels of glucocorticoids may be preferable due to detrimental effects of high levels on body condition and health [10]. The following discussion addresses the evidence to date to suggest functions of glucocorticoids in mate choice and sexual selection. 


\section{How do glucocorticoids influence mate choice?}

Human research offers excellent opportunities to test roles of stress in mate choice. There is evidence that cortisol (the primary human glucocorticoid) and testosterone are positively correlated [25], although this finding is not consistent (see for example [26, 27]) and may depend upon, for example, the intensity of recent exercise [28]. Sexually dimorphic facial characteristics derive from sex differences in the ratio of the male and female sex hormones that emerge at puberty (see for example [29]). A surge of testosterone in males during adolescence promotes cranio-facial bone growth resulting in heavier jaws and eyebrow ridges. These changes are inhibited in females by the action of oestrogen. In adulthood there are positive relationships between both circulating testosterone [30] and testosterone response to a challenge [31] and masculinity of the male face, as well as between oestrogen and femininity in female faces [32]. This means that there are cues to testosterone in the male face that we can parametrically manipulate using sophisticated digital face morphing techniques. Circulating levels of cortisol and testosterone can be measured using noninvasive methods that reduce activation of the stress response to provide an accurate estimate of baseline levels of the hormones. Furthermore, it is possible to obtain ratings by women of perceptions of facial stimuli that differ in cues to the hormones. These are luxuries not so easily afforded by work with other species and mean that we are able to identify any mediating or moderating role of cortisol on relationships between testosterone and attractiveness in a uniquely controlled way.

The relationship between sexual dimorphism and attractiveness is fairly consistent for female faces, with both men and women agreeing that the more feminine a face, the more attractive it is (see for example [33, 34]). For male faces, however, the story is more complicated, with variation in women's preferences suggestive of a trade-off in the relative importance of a committed, reliable partner versus a partner who signals "good genes". Given the relationship between testosterone and masculinity of the male face, masculine faced males may signal a robust immune system. While this is likely to be attractive to women seeking to secure a strong immune system for offspring, it must be balanced up against the negative personality characteristics that are attributed to the owners of masculine male faces, including dishonesty, low likelihood to commit to a relationship and aggression (see for example [35, 36]). This perhaps explains why women tend to prefer feminine-faced men who are attributed with honesty, commitment and good parenting in general, but to switch to preferences for more masculine faces at times when the chances of conception are high including the fertile phase of the menstrual cycle (see for example [37]), when commitment is less important to mate choice decisions, such as when faces are judged for a short term rather than a long term relationship (see for example [38]) and in societies in which there is greater competition for resources [39] or in which the costs of ill health are high [40].

In a sample of 69 Scottish male students, my colleagues and I measured testosterone and cortisol from saliva samples collected by passive drool at two time-points (one in the morning and one in the afternoon), to control for circadian fluctuations in both hormones, 
using enzyme-linked immunosorbant assays. Mean testosterone leves ranged from 0.07 $0.63 \mathrm{ng} / \mathrm{mL}$, and mean cortisol from $3.7-24.04 \mathrm{nmol} / \mathrm{L}$. We also took facial photographs of participants under standardized conditions (e.g. with diffuse flash lighting, at the same distance from the camera and with glasses removed and neutral expression). We assessed the effects of testosterone and cortisol on facial attractiveness in two ways. First, we asked a sample of female participants to rate the faces for attractiveness, masculinity and health on $1-7$ scales $(1=$ not at all attractive/masculine/healthy, $7=$ extremely attractive/masculine/healthy). The faces of males with low cortisol were rated as significantly more attractive than those with high cortisol $\left(\mathrm{r}^{2}=-0.36, \mathrm{p}=0.027\right)$. There were no relationships between cortisol, health and masculinity and, unlike previous studies ([37] for example), testosterone was not related to women's perceptions of the faces (all $p>0.3$ ). Next, we used the face morphing software Psychomorph to create "composite" facial images which contained cues to combinations of high and low levels of testosterone and cortisol [41]. For this, we identified groups of $5-6$ males with the following combinations of hormones, based on median splits: high testosterone and high cortisol, high testosterone and low cortisol, low testosterone and high cortisol, low testosterone and low cortisol. We then "averaged" together the faces of the participants in each of these groups to give composite stimuli containing cues to the 4 combinations of hormones (see Figure 1).

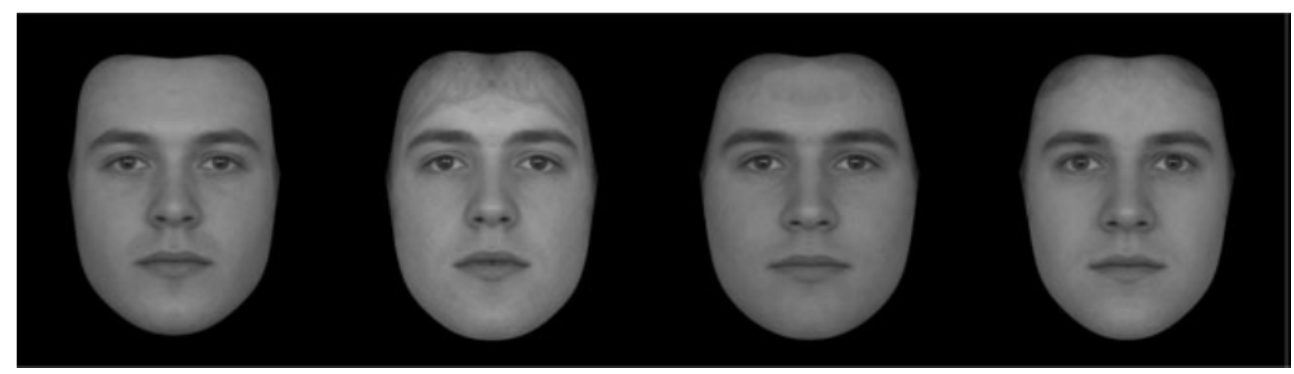

Figure 1. Composite male faces constructed to differ in combinations of testosterone and cortisol. From left to right: high testosterone with high cortisol, high testosterone with low cortisol, low testosterone with high cortisol, low testosterone with low cortisol. Taken from Moore et al. 2011. Proceedings of the Royal Society of London Series B, doi:10.1098/rspb.2010.1678.

The stimuli were then rated by a novel sample of female participants during the fertile and non-fertile phases of their menstrual cycles. Using mixed model Anova, we found that women consistently preferred the low cortisol composites $\left(\mathrm{F}_{(1,42)}=5.11, \mathrm{p}=0.029\right)$. Post hoc analyses revealed that this effect was significant in the fertile $\left(F_{(1,42)}=6.44, p=0.015\right)$, but not the non-fertile $(p>0.1)$ cycle phase (see Figure 2$)$. We concluded that women can detect cues to cortisol in the male face, and that low cortisol is desirable in a male partner. We also suggested that low cortisol may be associated with beneficial heritable characteristics as women expressed the strongest preferences for facial cues to low cortisol at times when they were most likely to conceive [26]. 


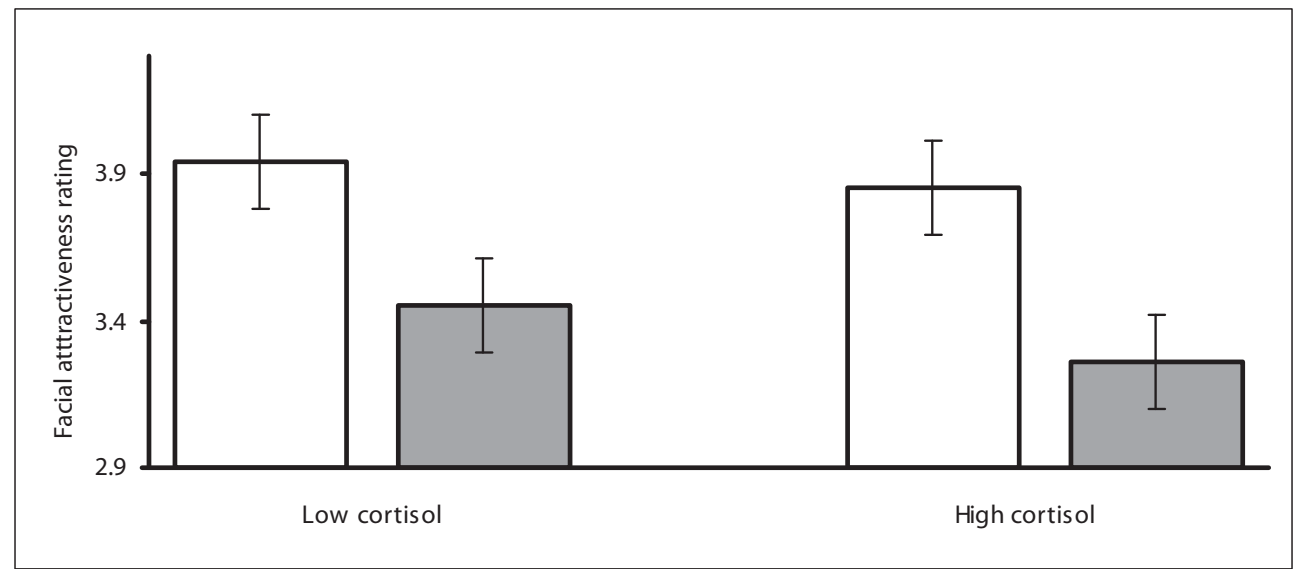

Figure 2. Mean attractiveness ratings of composite male faces constructed to differ in cues to cortisol by women during the non-fertile (empty bars) and fertile (filled bars) phases of their menstrual cycles with error bars showing +- $1 \mathrm{SE}$. In a mixed model anova there was a significant effect of cortisol on attractiveness $\left(\mathrm{F}_{(1,42)}=5.11, \mathrm{p}=0.029\right)$. Post hoc tests revealed that this effect was significant only during the fertile phase of the cycle $\left(F_{(1,42)}=6.44, p=0.015\right)[26]$.

We replicated this pattern of results in a different sample of faces with a novel sample of female raters, again recruited from UK student populations. Once again, women preferred the faces of males with low cortisol, and didn't express preferences for testosterone. In this second study, we also tested the effects of the hormones on perceived dominance and health, finding that low cortisol faces were also rated as more dominant and healthy than high cortisol faces $[26,27]$. The findings of both studies are consistent with work in other species that shows that females prefer males with low levels of glucocorticoids. In [12], for example, the authors found that female zebra finch (Tynopygea guttatta) preferred males with low corticosterone, and expressed no preference for cues to testosterone. Spectrophotometric measures of plumage suggested that dimensions of plumage colour and brightness provided cues to the stress status of the male. Similarly, in [42] Leary and colleagues found that female great plains toads (Bufo cognatus) preferred the calls of males with low glucocorticoids. There is growing evidence, then, that glucocorticoids play a role in mate choice. Why this may be, however, is unclear.

\section{Glucocorticoids and testosterone}

One possibility is that the hormonal underpinnings in expression of sexual traits that have previously been attributed to testosterone are, in fact, due to the effects of the glucocorticoids (see for example [11]). If this were the case, however, we would expect to find effects of testosterone that disappear once glucocorticoids are controlled for statistically. Although this pattern of results was reported for a study of effects of the hormones on the immune function of the house sparrow, this has not been replicated in other species. It seems unlikely, then, that the role of stress is so straightforward. Rather than simple mediation of effects of testosterone by those of cortisol, in both of our studies described 
above we found an interaction between testosterone and cortisol, such that the detrimental effects of cortisol were stronger in those males with low testosterone compared to those with high testosterone (See Figure 3). We proposed that high testosterone males (i.e. those signalling the strength of their immune system) are better able to cope with the detrimental effects of stress [26, 27]. In order to test this explanation, however, it is necessary to experimentally manipulate stress in males who differ in their level of testosterone and test for any divergent effects on immune system and/or sexual signals.

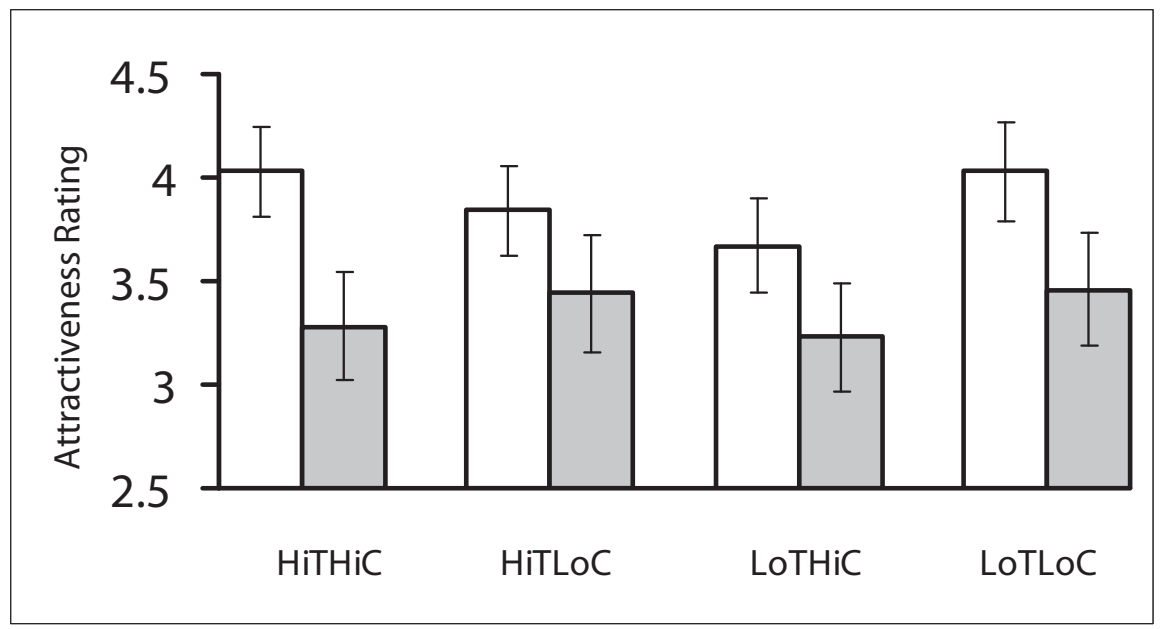

Figure 3. Mean attractiveness ratings of composite faces that differ in combinations of testosterone and cortisol (+1 s.e.) by women during the non-fertile (empty) and fertile (filled) phases of their menstrual cycles. The figure shows an interaction between the hormones, such that cortisol reduces attractiveness in males with low testosterone, but enhances it in males with high testosterone. Taken from Moore et al. 2011. Proceedings of the Royal Society of London Series B, doi:10.1098/rspb.2010.1678.

While we have replicated the interaction between testosterone and cortisol in two UK samples, in a recent attempt to determine whether our results extend across human populations, we found evidence to suggest that the effects of combinations of sex and stress hormones on facial appearance are population-dependent. In a third study, we tested relationships between testosterone, cortisol and facial attractiveness in a sample of 74 male students. This time we tested relationships across the faces of individual males, rather than in digitally manipulated composite faces and measured testosterone and cortisol from intravenous blood samples rather than from saliva as this allowed us to take simultaneous measurements of immune function. Contrary to previous studies, we found a positive relationship between testosterone and men's facial attractiveness, but no relationship between cortisol and attractiveness. While we found an interaction between testosterone and cortisol in effects on facial attractiveness, it's nature differed to that reported in our previous studies such that this time the positive relationship between testosterone and attractiveness was strongest in those males with low cortisol [43]. See Figure 4. 


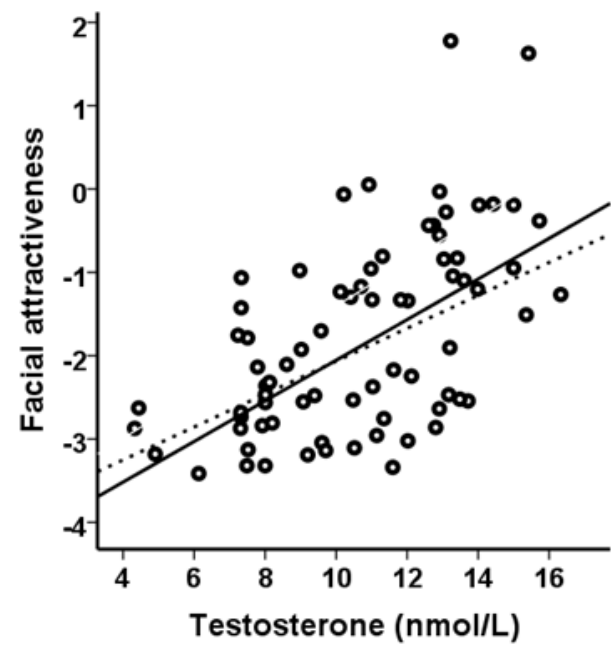

(a)

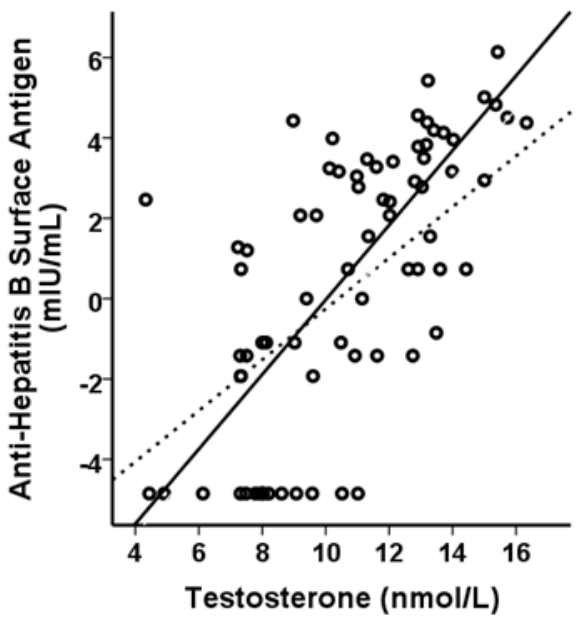

(b)

Figure 4. Relationships between testosterone and (a) facial attractiveness in a sample of Latvian male students rated by female participants drawn from the same population, showing an interaction with cortisol such that the relationship was strongest in those males with low cortisol (solid line) and weakest in those with high cortisol (broken line) and (b) antibody response to a hepatitis B vaccine, showing an interaction with cortisol such that the relationship was strongest in those males with low cortisol (solid line) and weakest in those with high cortisol (broken line). From [43].

Why should we find differences in the nature of the interaction between testosterone and cortisol on facial attractiveness between our samples? It seems unlikely that we can attribute this to differences in our methods. In all 3 studies we tested for relationships between the hormones and face perceptions across individual faces and failed to find interactions between testosterone and cortisol in either of the first two studies. Does the construction of composites result in spurious results? Only further testing will adequately test this, but an alternative possibility is that societal-level factors cause systematic variation in the effects of sex- and stress- hormones (and combinations of the two) on attractiveness. While the samples in our first two studies were taken from populations of UK students, the sample for our third study - the one in which we found a different interaction between the hormones was drawn from a sample of male students and female raters from the University of Daugavpils in Latvia. Could societal-level differences in the strategies employed by women to assess the attractiveness of male faces underpin the differences we report in the effects of sex- and stress-hormones on facial attractiveness? There is evidence to suggest that this could be the case. In [40], for example, Debruine and colleagues reported that societal level health measures were related to women's preferences for cues to testosterone in the male face. That is, women in societies in which the costs of ill health are high express stronger preferences for cues to high testosterone. Perhaps, then, cultural differences in the provision of healthcare, or in other social and economic factors, cause the female raters in our samples to express divergent preferences for cues to testosterone and/or cortisol, which in turn will 
influence the nature of the interaction between the two. This is insightful as identification of the socioecological factors that underpin variation in preferences for cues to the hormones can contribute to our understanding of the traits and characteristics that they signal. My collaborators and I are currently conducting further cross-cultural research to achieve this.

That population-level differences in socioecology could influence the nature of the role of stress in mate choice is further supported by cross-species differences in interactions between testosterone and glucocorticoids on sexual traits. Such interactions have been reported in several avian species. In the red grouse, for example, a positive relationship between testosterone and comb area was stronger in males with low levels of co-occurring glucocorticoids than in those with physiological markers of high stress [44]. Conversely, in the red bishop (Euplectes orix), the relationship between testosterone and plumage colour was inverse under high stress, but positive or non-significant under low stress [45]. Despite evidence, then, that testosterone-dependent signalling is contingent upon concurrent stress, the nature of interactions between sex and stress hormones is inconsistent.

In order to begin to interpret the meaning of this inconsistency, it is necessary to understand a little more about how the two hormones interact at a physiological level. One way is through competition for binding sites on the two types of glucocorticoid receptor. The first of these has a high affinity for the stress hormones, so glucocorticoids tend to bind to these first, meaning that the receptors are typically saturated at peak points in the circadian cycle and therefore serve primarily to regulate circadian rhythms. The second type, although more abundant, have a lower binding affinity, so tend to bind once all the first type are engaged. These, then, are the receptors that are bound during response to a stressor and regulate the stress response [46]. This means that baseline and peak response glucocorticoids can be conceptualized as different hormonal systems as their binding to different types of receptors results in divergent effects on physiology and behaviour [46]. As the proteins which bind glucocorticoids (corticosteroid binding globulins) can also bind testosterone, there may be competition between the hormones for binding sites - particularly in avian species who lack independent sex steroid binding globulins $[47,48]$. It is possible, for example, that elevated glucocorticoids reduce the numbers of receptors available for testosterone, reducing bound levels and increasing free levels which may influence effects of testosterone on behaviour and signalling. Perhaps, then, relationships between testosterone and glucocorticoids, and their combined effects on sexual signals, depend upon the species and the dimension of the stress response that is measured (e.g. peak versus baseline).

\section{Immunocompetence}

The "stress-linked" model of hormonally-mediated sexual selection as originally proposed over a decade ago [11, 49], in acknowledgement of increasing awareness that extant endocrinological models did not sufficiently explain variation in the cross-species data, proposed that effects of glucocorticoids on sexual traits were likely to occur through their effects on the immune system. Despite evidence for an immunomodulatory role of stress, meaning that this seems to be a viable possibility, it poses a difficult problem to address, and an even more difficult system to model, as it is not simply the case that stress 
suppresses the immune system. Depending upon the nature, duration and predictability of a stressor, for example, stress can enhance, suppress or redistribute immune activity [24]. How, then, can we model and test roles of stress in sexual selection that are mediated by effects on the immune system? To date, a handful of studies of avian species have tested inter-relationships between stress, immune function and sexual signalling demonstrating complex relationships between immune function, stress and sexual signals. A study of red grouse, for example, reported a positive relationship between glucocorticoids and parasite load and an inverse relationship between parasite load, and testosterone-dependent ornament (i.e. supraorbital comb) area [44]. Similarly, a study of blue tits (Cyanistes caeruleus) demonstrated parasite load to be positively related to a physiological marker of stress (heat shock proteins) and inversely to sexually selected colouration [50]. Conversely, a study of song sparrows (Melospiza melodia) reported no relationship between stress and immune function [51], meaning that detrimental effects of stress on song repertoire were not mediated by immunocompetence. In our work with human faces, my colleagues and I found that the pattern of the interaction between testosterone and cortisol on attractiveness was mirrored by the same pattern in effects on antibody response to a vaccine [43]. See Figure $4 \mathrm{~b}$. While there is some evidence, then, to suggest that the combined effects of testosterone and cortisol on sexual signalling are concurrent with those on immune function, it seems likely that such results are dependent upon the arm of the immune system that is assessed as well as the measurement of stress.

\section{Stress and body condition}

Husak and Moore [10] suggested that glucocorticoids could influence the intensity of sexual signals via their detrimental effects on body condition. If stress reduces body condition (e.g. body mass and/or fat stores), an individual who is experiencing stress is less likely to be able to afford to allocate energy and metabolic resources to sexual signalling. Effects of stress on body condition, however, are inconsistent, with studies from some species showing that stress reduces body condition (song sparrow (Melospiza melodia) [51]; upland geese (Chloephaga picta) [52]; zebra finches [53]), others showing stress to increase body condition (Beldings ground squirrels (Spermophilus beldingi) [54]) and still others showing no effect (e.g. mallard ducks (Anas platyrhynchos) [55]). Furthermore, few studies have shown effects of stress on sexual signals that were consistent with those on condition. An exception is the red grouse, in which parasite load was shown to reduce body condition, increase physiological markers of stress and reduce the expression of plumage colouration [56]. The evidence, then, suggests that any effects of stress on sexual signals do not occur via its action on body condition. In fact, in some cases, stress may cause a reallocation of resources away from body condition and into sexual signalling. Positive relationships between stress and the expression of carotenoid - based colouration at the cost of condition have been reported in the zebra finch [53] and the common lizard [57]. This suggests that, in some cases, stress causes a redistribution of energy and resources away from long term goals and instead to short term priorities (e.g. mating). This would seem to be a sensible strategy when, for example, survival was threatened, which may be signalled by elevated stress hormones. 


\section{Stress Ebehaviour}

In addition to sexual signals such as ornaments, colouration or song, stress also impacts upon behaviours relevant to reproduction. There may, then, be behavioural cues to glucocorticoid status which females make use of in their mate choice decisions, or stressdependent sexual signals may provide insight into an individual's likely behaviour. Activation of the hypothalamic-pituitary-adrenal axis in response to stress suppresses the hypothalamic-pituitary-gonadal axis which is responsible for mediating sexual behaviour [58], resulting in reduced expression of sexual behaviours. One mechanism, for example, by which stress suppresses reproductive behaviour is via inhibition of the gonadotropin protein hormones which regulate reproductive function by glucocorticoids [59, 60]. It is well known that chronically elevated stress suppresses reproduction by, for example, reducing sex drive, courtship behaviour and fertility(see for example [61 - 63]). There is also evidence that acutely elevated glucocorticoids have a similar outcome with, for example, glucocorticoids elevated by fasting reducing courtship behaviour such as singing in the male zebra finch [64] and the locomotor activity that contributes to foraging and reproduction in male Allegheny dusky salamanders (Desmognathus ochrophaeus;[65]). Elevated glucocorticoids are also associated with reduced provisioning of offspring (see for example [66]).It is possible, then, that females attend to behavioural indications of high stress, or that stress-dependent sexual signals provide an indication of reproductive function and/or ability to provision offspring. Avoiding individuals who are currently experiencing stress will reduce the chances of attempting to mate with a member of the opposite sex with reduced reproductive function and/or ability to provision offspring, thereby allowing the female to maximise her reproductive success.

There are also relationships between stress and dominance, although these are typically complex and dependent upon, among many others, both the status of an individual in a hierarchy and the stability of the social structure. Attention to cues to stress, then, may enable an individual to select an opposite sex partner who occupies a high status position in a dominance hierarchy, with associated high status and access to premium resources, ensuring high status, well-provisioned offspring. It is not simply the case, however, that high stress is a cue to low rank in a hierarchy. Creel [67], for example, demonstrates that, although agonistic social interactions can provoke a large glucocorticoid response, in established social groups, where individuals know the hierarchy, such responses are not necessarily the case and in some cooperative breeding species (i.e. a social system in which individuals contribute to the care of others' offspring) such as the meerkat (Suricata suricatta), for example, dominant individuals may have higher glucocorticoids that subordinates. It seems likely that divergent levels of stress hormones in accordance with strata of the social structure are dependent upon both the nature of the hierarchy which is, in turn, dependent upon species socioecology but also upon stability of the hierarchy. In unstable structures, if dominant individuals are involved in the most agonistic encounters, then it is the dominant individuals who experience the highest levels of stress. In mallards and pintails (Anas acuta; [55]), bison (Bison bison; [68]) and ring necked pheasants (Phasianus colchicus; [56]), for example, dominant males have higher levels of glucocorticoids than 
subordinate males. It seems likely, then, that if cues to stress are used to infer information about a potential partner's dominance status or, vice versa, if dominance status influences stress levels, the direction of such relationships will be species dependent.

\section{Future research}

Despite evidence to suggest that glucocorticoids play a role in sexual selection and mate choice, the nature and function of that role remains unclear. The effects of stress, while typically serving to reduce male attractiveness and the expression of sexual signals, are not consistent with some studies showing positive effects. Furthermore, despite proposals that the effects of stress occur through its action on immune function and/or body condition, there is little evidence to support this. Therefore, while we know that females prefer males with cues to low levels of stress hormones, we do not yet know what cues they attend to or what is signalled by "low stress". Despite a growing body of research, then, we are still confronted by a number of unknowns. Is it the case, for example, that males signal their current stress status? Or do they rather signal their ability to respond optimally to a stressor (i.e. an adaptive response which promotes survival but reduces the detrimental costs to health)? Are all sexual traits and signals similarly influenced by stress? That is, does stress affect those traits which show great plasticity during adulthood (e.g. plumage colouration in birds, or skin health in humans) differently to those which emerge at set developmental stages (e.g. bird song or human facial sexual dimorphism). Is the link with immune function so complex that we have to look at redistribution of resources across the arms of the immune system in response to chronic versus acute, and predictable versus unpredictable stressors? To begin to answer these questions, and to model roles of stress in mate choice, it is now necessary to test the effects of baseline stress, and of dimensions of the stress response (e.g. total amount of glucocorticoids produced in response to a standardised stressor and time to return to baseline) on different types of sexual signals (e.g. those that are typically dependent upon current condition versus those that develop at set life history stages) and to interpret findings in the context of species and population ecology [69]. Crosscultural and cross-species comparisons can likewise contribute to our understanding of the traits signalled by low glucocorticoids.

\section{Conclusion}

To summarise, then, there is a growing body of evidence to show that the glucocorticoid hormones are implicated in mate choice and sexual selection. Women prefer the faces of males with low levels of cortisol, for example, and female zebra finch prefer males with low levels of corticosterone. We do not know, however, why females express these preferences as it is not yet clear what characteristics are signalled by cues to low glucocorticoids. Suggestions in the literature are that stress reduces body condition or suppresses the immune system which, in turn, reduce the extent to which individuals seek to attract members of the opposite sex. The extant evidence, however, does not consistently support these theories. It has also been proposed that stress mediates the effect of testosterone on sexual signals. Again, there is little support for this with results instead suggesting an 
interaction between testosterone and glucocorticoids - the nature of which is dependent upon the species, population and, in all likelihood, current socioecological conditions. What is clear is that there is increasing evidence for stress in sexual selection. It is now necessary to seek to better understand and model its precise roles and functions by conducting research which clearly operationalises the dimension of the stress response and the type of trait under investigation.

\section{Author details}

Fhionna R. Moore

School of Psychology, College of Art and Social Science, University of Dundee, UK

\section{Acknowledgement}

I am grateful to Kate Buchanan for insightful comments on a related draft and to Indrikis Krams, Markus Rantala and Vinet Coetzee for interesting discussions on the roles of stress in sexual selection.

\section{References}

[1] Darwin C (1859) On the Origin of Species by Means of Natural Selection, or the Preservation of Favoured Races in the Struggle for Life. John Murray, London; modern reprint Charles Darwin, Julian Huxley.

[2] Darwin C (1871) The Descent of Man and Selection in Relation to Sex. John Murray, London

[3] Petrie M, Halliday T, Sanders C (1991) Peahens prefer peacocks with elaborate trains. Anim. Behav. 41: 323-331.

[4] Borgia G (1985) Bowers as markers of male quality. Tests of a hypothesis. Anim. Behav. 33: 266-271.

[5] Grafen A (1990) Biological signals as handicaps. J. Theor. Biol 144:517-546.

[6] Zahavi A (1975) Mate selection - a selection for a handicap. J. Theor. Biol. 53: 205-214.

[7] Folstad I, Karter A J (1992) Parasites, bright males and the immunocompetence handicap. Am. Nat. 139: 603-622.

[8] Hamilton W D, Zuk M (1982) Heritable true fitness and bright birds: a role for parasites? Science 218: 384-387.

[9] Buchanan K L (2000) Stress and the evolution of condition dependent signals. Trends Ecol. Evol. 15: 156-160.

[10] Husak J F, Moore I T (2008) Stress hormones and mate choice. Trends Ecol. Evol. 23: 532-534.

[11] Evans M R, Goldsmith A R, Norris, S R A (2000) The effects of testosterone on antibody production and plumage colouration in male house sparrows (Passer domesticus). Behav. Ecol. Sociobiol. 47: 156-163. 
[12] Roberts M L, Buchanan K L, Bennett A T D, Evans M R (2007) Mate choice in zebra finches: does corticosterone play a role? Anim. Behav. 74: 921-929.

[13] Hill G E, McGraw K J (2006). Bird Coloration. Vol. 2: Function and Evolution. Cambridge, Massachusetts: Harvard University Press

[14] Lindsay W R, Webster M S, Schwabl H (2011) Sexually selected male plumage colouration is testosterone dependent in a tropical passerine, the red-backed fairy wren (Malanus melanocephalus). PLoS One 6: e26067.

[15] Malo A F, Roldan E R S, Garde J J, Soler A J, Vicente J, Gortazar C, Gomendio A (2009) What does testosterone do for red deer males? Proc. Roy. Soc. B 276: 971-980.

[16] Price J, Allen S (2004) Exploring the mechanism regulating regeneration of deer antlers. Phil. Trans. R. Soc. B 359: 809-822.

[17] Ritschard M, Laucht S, Dale J, Brumm H (2011) Enhanced testosterone levels affect singing motivation but not song structure in Bengalese finches. Physiol. Behav. 102: 3135.

[18] Saldanha C, Clayton N, Schlinger B (1999) Androgen metabolism in the juvenile oscine forebrain: a cross-species analysis at neural sites implicated in memory function $\mathrm{J}$. Neurobiol. 33: 619-631.

[19] Roberts M L, Buchanan K L, Evans M R (2004) Testing the immunocompetence handicap hypothesis: a review of the evidence. Anim. Behav. 68: 227-239.

[20]. Deviche P J, Hurley L L, Fokidis H B, Lerbour B, Silverin B, Silverin B, Sabo J, Sharp (2010). Acute stress rapidly decreases plasma testosterone in a free-ranging male songbird: Potential site of action and mechanism. Gen. Compar. Endocrin. 169: 82-90.

[21] Gratto-Trevor C L, Oring L W, Fivizzani A J (1991) Effects of blood sampling stress on hormone levels in the semipalmated sandpiper. J. Field Ornithol. 62: 19-27.

[22] Owen-Ashley N T, Hasselquist D, Wingfield J C (2004) Androgens and the immunocompetence handicap hypothesis: unravelling direct and indirect pathways in song sparrows. Am. Nat. 164: 490-505.

[23] Moore I T, Lerner J P, Lerner, D T, Maso R T (2000) Relationships between Annual Cycles of Testosterone, Corticosterone, and Body Condition in Male Red-Spotted Garter Snakes, Thamnophis sirtalis concinnus. Physiolog. Biochem. Zool. 73:307-312.

[24] Martin L B (2009) Stress and immunity in wild vertebrates: timing is everything. Gen. Compar. Endocrinol. 163: 70-76.

[25] Mehta P H , Josephs R A (2010) Testosterone and cortisol jointly regulate dominance: Evidence for a dual-hormone hypothesis. Horm. Behav.58: 898-906.

[26] Moore F R, Cornwell R E, Law Smith M J, Al Dujaili E A S, Sharp M, Perrett D I (2011) Tests of the stress-linked immunocompetence handicap hypothesis in human male faces. Proc. Roy. Soc. B278: 774-780.

[27] Moore F R, Al Dujaili E A S, Cornwell R E, Law Smith M J, Lawson J F, Sharp M, Perrett D I (2011) Cues to sex and stress hormones in the human male face: functions of glucocorticoids in the immunocompetence handicap hypothesis. Horm. Behav. 60: 269274.

[28] Brownlee K K, Moore A W, Hackney A C (2005) Relationship between circulating cortisol and testosterone: influence of physical exercise. J. Sports Sci. Medicine 4: 76-83. 
[29] Enlow D H (1990) Facial growth, 3rd edn. Philadelphia, PA: Harcourt Brace Jovanovich

[30] Penton-Voak I S\& Chen J Y (2004) High salivary testosterone is linked to masculine male facial appearance in humans.Evol. Hum. Behav. 25: 229-241.

[31] Pound N, Penton Voak I S, Surridge A K (2009) Testosterone responses to competition in men are related to facial masculinity. Proc. Roy. Soc. B. 276: 153-159.

[32] Law Smith M J, Perrett D I, Jones B C, Cornwell R E, Moore F R, Feinberg D R, Boothroyd L G, Stirrat M R, Whiten S, Pitman R M, Hillier S G (2006) Facial appearance is a cue to oestrogen levels in women. Proc. Roy. Soc. B 273: 135-140.

[33] Perrett D I, Lee K J, Penton-Voak I, Rowland D R, Yoshikawa S, Burt D M, Henzi S P, Castles D L, Akamatsu S (1998) Effects of sexual dimorphism on facial attractiveness. Nature 394: 884-887.

[34]Moore F R, Taylor V, Law Smith M J, Perrett D I (2011) Sexual dimorphism in the female face is a cue to health and social status but not age. Pers. Ind. Diff. 50: 1068-1073.

[35] Boothroyd L G, Jones B C, Burt D M, Perrett D I (2007) Partner characteristics associated with masculinity, health and maturity in male faces. Pers. Ind. Diffs. 43: 1161-1173.

[36] Swaddle J, Reierson G (2002) Testosterone increases perceived dominance but not attractiveness. Proc. Roy. Soc. B 269: 2285-2289.

[37] Penton Voak I S, Perrett D I, Castles D L, Kobayashi T, Burt D M, Murray L K, Minamisawa R (1999). Menstrual cycle alters face preferences. Nature 399: 741-742.

[38] Waynforth D, Delwadia S, Camm. (2005). The influence of women's mating strategies on preference for masculine facial architecture. Evol. Human Behav. 26: 409-416.

[39] Brooks R, Scott I M, Maklakov A A, Kasumovic M M, Clark A P, Penton-Voak I S. 2011. National income inequality predicts women's preferences for masculinised faces better than health does. Proc. R. Soc. B 278: 810-812.

[40] DeBruine L M, Jones B C, Crawford J R, Welling L L M, Little A C (2010) The health of a nation predicts their mate preferences: cross-cultural variation in women's preferences for masculinized male faces. Proc. R. Soc. B 277: 2405-2410.

[41] Tiddeman B, Burt, M, Perrett, D I (2001) Prototyping and Transforming Facial Textures for Perception Research. IEEE Computer Graphics and Applications 21: 42-50.

[42] Leary C J, Jessop T S, Garcia A M, Knapp R (2004). Steroid hormone profiles and relative body condition of calling and satellite toads: implications for proximate regulation of behavior in anurans. Behav. Ecol. 15: 313-320.

[43] Rantala M J, Moore F R, Skrinda I, Krama T, Kivleniece I, Kecko S, Krams I (2012) Evidence for the stress-linked immunocompetence handicap hypothesis in humans. Nature Comms. DOI: 10.1038/ncomms1696.

[44] Bortolotti G R, Mougoet F, Martinez-Padilla J, Webster L M I, Piertney S B (2009) Physiological stress mediates the honesty of social signals. PloS One 4: e4983.

[45] Edler A V, Friedl T W P (2010) Individual quality and carotenoid-based plumage ornaments in male red bishops (Euplectes orix): plumage is not all that counts. Biol. J. Linn. Soc. 99: 384-397.

[46] Romero L M (2004) Physiological stress in ecology: lessons from biomedical research. Trends in Ecol Evol. 19: 249-255. 
[47] Klukowski L A, Cawthorn J M, Ketterson E D, Nolan Jr. V (1997) Effects of experimentally elevated testosterone on plasma corticosterone and corticosteroidbinding globulin in dark-eyed juncos (Junco hyemalis). Gen. Comp. Endocrinol. 108: 141151.

[48] Swett MB, Breuner CW (2008) Interaction of testosterone, corticosterone and corticosterone binding globulin in the white-throated sparrow (Zonotrichia albicollis). Comp Biochem Physiol A Mol Integr Physiol. 151: 226-31.

[49]Møller A P (1995) Hormones, handicaps and bright birds. Trends Ecol. Evol. 10: 121.

[50] del Cerro S, Merino S, Martinez-de la Puerte J, Lobato E, Ruiz-de-Castañeda Rivero-de Aguilar J Martinez J, Morales J, Tomás G, Moreno J (2010). Carotenoid-based plumage colouration is associated with blood parasite richness and stress protein levels in blue tits (Cyanistes caeruleus). Oecologia 162: 825-835.

[51] Pfaff J A, Zanette L, MacDougall-Shackleton S A, MacDougall-Shackleton E A (2007) Song repertoire size varies with HVC volume and is indicative of male quality in song sparrows (Melospiza melodia). Proc. R. Soc. B. 274: 2035-2040.

[52] Gladbach A, Gladbach D J, Quillfeldt P (2010) Variations in leukocyte profiles and plasma biochemistry are related to different aspects of parental investment in male and female upland geese Chloephaga picta leucoptera. Comp. Biochem. Physiol. A. 156: 269277.

[53] McGraw K J, Lee K, Lewin A (2011) The effect of capture-and-handling stress on carotenoid-based beak coloration in zebra finches. J. Comp. Physiol. A. 197: 683-691.

[54] Nunes S, Pelz K M, Muecke E-M, Holekamp K E, Zucker I (2006). Plasma glucocorticoids concentrations and body mass in ground squirrels: seasonal variation and circannual organisation. Gen. Compar. Endocrin. 146: 136-143.

[55] Poisbleau M, Fritz H, Guillon N, Chastel O (2005) Linear social dominance hierarchies and corticosterone responses in male mallards and pintails. Horm. Behav. 47: 485-492.

[56] Mateos C (2005) The subordination stress paradigm and the relation between testosterone and corticosterone in male ring-necked pheasants. Anim. Behav. 69: 249255.

[57] Cote J, Meylan S, Clobert J, Voituron Y (2010) Carotenoid-based colouration, oxidative stress and corticosterone in common lizards. J. Experiment. Biol. 213: 2116-2124.

[58] Breen K M, Stackpole C A, Clarke I J, Pytlak A V, Tilbrook, A J, Wagenmaker E R, Young E A, Karsch F J (2004) Does the type II glucocorticoid receptor mediate cortisolinduced suppression in pituitary responsiveness to gonadotropin-releasing hormone? Endocrinology 145: 2739-2746.

[59] Attardi B, Klatt B, Hoffman G E, Smith M S (1997) Facilitation or inhibition of the estradiol-induced gonadotropin surge in the immature rat by progesterone: regulation of $\mathrm{GnRH}$ and $\mathrm{LH}$ messenger RNAs andactivation of GnRH neurons. J. Neuroendocrinol. 9: 589-599.

[60] Attardi B, Pfaff D W, Fink G (1999) Actions of progesterone on the pituitary in relation to facilitation of the estradiol induced gonadotropin surge in the immature rat. Soc. Neurosci. Abstr. 582: 13. 
[61] Greenburg N, Wingfield J C (1987) Stress and reproduction: reciprocal relationships. D.O. Norris, R.E. Jones (Eds.), Reproductive Endocrinology of Fishes, Amphibians and Reptiles, Wiley, New York, pp. 389-426

[62] Menendez-Patterson A, Florez-Lozano J A, Fernandez S, Marin B (1980) Stress and sexual behavior in male rats. Physiol. Behav. 24: 403-406.

[63] Moberg GP (1991) How behavioral stress disrupts the endocrine control of reproduction in domestic animals J. Dairy Sci. 74: 304-311.

[64] Lynn S E, Stamplis T B, Barrington W T, Weida N, Hudak C A (2010) Food, stress, and reproduction: Short-term fasting alters endocrine physiology and reproductive behavior in the zebra finch. Horm. Behav. 58: 214-222.

[65] Ricciardella L F, Bliely J M, Feth, C C, Woodley, S K (2010). Acute stressors increase plasma corticosterone and decrease locomotoractivity in a terrestrialsalamander (Desmognathus ochrophaeus). Physiol. Behav. 101: 81-86.

[66] Tilgar V, Moks K, Saag P (2011) Predator-induced stress changes parental feeding behavior in pied flycatchers.Behav. Ecol. 22:23-28.

[67] Creel S (2001) Social dominance and stress hormones. Trends in Ecol Evol. 18: 491-198.

[68] Mooring M S, Patton M L, Lance V A, Hall B M, Schaad E W, Fetter G A, Fortin S S, McPeak K M Glucocorticoids of bison bulls in relation to social status. Horm. Behav. 49: 369-375.

[69] Evans M R (2010) Why does testosterone influence morphology, behaviour and plasticity? Open Ornithol. J. 3: 21-26. 